\title{
Analyze the Production System of an Body-In-White System Through Modelling And Perform Bottleneck, Optimization Using Simulation Software
}

\author{
D. PHANINDRA KSHATRA, P. RATNA PRASAD, MD. KALAMULLA, P.SAI KRISHNA, \\ P.B.L.N. SAI
}

\begin{abstract}
For a system to improve its productivity, optimizing it, and increase the overall efficiency of a Plant, a bottleneck is a key issue. Bottlenecks influence the efficiency and throughput of the plant. The presented Discrete Event Simulation (DES) model is one the method to analyze problems within the layout. The objective of the paper is to perform bottleneck analysis, optimization of an automobile production plant layout. The virtual environment of batch mode layouts is built by Tecnomatix simulation software. Throughput bottlenecks were identified on a real-time basis by shifting bottlenecks method. The paper illustrates that the system can be optimized by high work station utilization through managing bottlenecks with the addition of buffers
\end{abstract}

Index Terms: Tecnomatix, Bottleneck, scheduling, optimization.

\section{INTRODUCTION}

Production is a refining process where the raw material is processed into a useful product. The real-time production lines are very complicated with classic numerical controlled machines, assembly stations, robots, conveyors. Industries always look at their productivity, whether to improve flexibility either by cost reduction or by increasing their sales. Simulation models evaluate different models of production with new strategies which allow us to locate bottlenecks during material flow. The department of industrial engineering and management at the University of West Bohemia has been dealing with DES and optimization of the production process for several years. Various results of simulation studies have been published e.g (Horejsi, Latif, Ulrych,2011).

Revised Manuscript Received on July 05, 2019

D.Phanindra Kshatra, Department of Mechanical Engineering, Koneru Lakshmaiah Education Foundation, Vaddeswaram, Vijayawada,

P. Ratna Prasad, Department of Mechanical Engineering, Koneru Lakshmaiah Education Foundation, Vaddeswaram, Vijayawada, India.

Md. Kalamulla, Department of Mechanical Engineering, Koneru Lakshmaiah Education Foundation, Vaddeswaram, Vijayawada, India.

P.Sai Krishna, Department of Mechanical Engineering, Koneru Lakshmaiah Education Foundation, Vaddeswaram, Vijayawada, India.

P.B.L.N.Sai, Department of Mechanical Engineering, Koneru Lakshmaiah Education Foundation, Vaddeswaram, Vijayawada, India.
One issue is to arrange the tasks in the production line that is to be performed. An efficient way to resolve this issue is balancing the lines and work stations. Line balancing means leveling, assigning works to stations, the workload to all operations along the lines in such a way that, optimization and bottleneck process are performed simultaneously. The assembly line balancing was proposed in 1961 by helgson. Line balancing is allocating of orders and scheduling lines according to product setting, due dates. Dynamic balancing is followed by most of the automobile production lines to avoid labor idleness and improve productivity. Line balancing technique mainly depends upon cycle time, lead time, bottleneck, idle time, downtime.

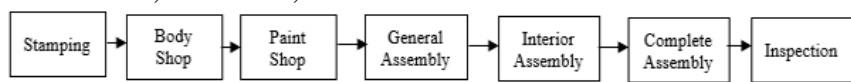

Fig 1: Automobile Manufacturing Layout

\section{PROBLEM STATEMENT}

A. What is the throughput (final number of products)? It is the time required for a product to pass through a manufacturing process, thereby converting raw materials into finished goods. It is the most natural thing to reduce manufacturing throughput time by eliminating as much inspection, move, and queue time as possible. Throughput is net sales minus totally variable expenses give us the final value.

B. How many numbers of bottlenecks are present and what are they?

When bottleneck issue arises, all other parts in the department slow down the system to accommodate it and materials accumulate along the production line - causing unnecessary downtime and in some cases a loss of revenue or profits. Bottlenecks can result in material accumulation and additional downtime between processes.

C. How big should the buffers before the bottlenecks be?

The larger the buffers, the less likely it is that a bottleneck will shift. Through decoupling, there will be an increase in inventory and system response time becomes more sluggish. Buffer is used to reducing

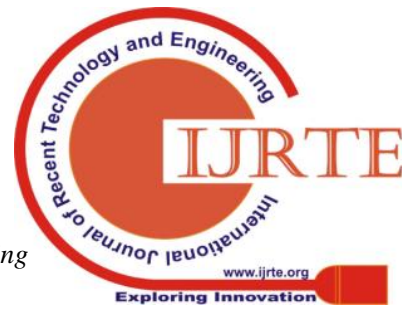


bottleneck by decoupling your bottleneck, Update or install new machines, improve changeovers, reduce scrap, improve maintenance.

\section{Literature SURVEY}

Betterton, 2012; Hsiao et al., (2010) [1]

A bottleneck is determined as a workstation limiting the production efficiency of the entire process.

Hromada \& Plinta et al., (2000) [2]

Simulation allows us to use new strategies and procedures, verification of the production in the revised system, locate bottlenecks in the flow of materials, increase productivity while reducing inventory and reduce the cost of the implemented changes.

Abu Qudeiri et al., (2008) [3]

Used a genetic algorithm for studying the design of a serial-parallel production line they tried to find the nearest optimal design of a serial-parallel production line that maximized production by optimizing buffer

Stanley and Kim et al., (2012) [4]

Presented results of simulation experiments made for buffer allocation in closed serial-production line. For a line, single buffer space in the room and the associated (material) handling equipment that is needed to store a single job that is a work-in-process, and buffer allocation is the specific placement of a limited number of buffers in a production line.

Limere.v et al., (2009) [5]

A Lot of parts need to be stored at the line, to be consumed when the corresponding chassis passes the work station. The parts can be bulk fed or brought at a line. In the case of bulk, this results in a huge amount of buffers at the border of the line

Goldratt et al., (2004) [6]

Identifying a bottleneck in the system is the first stage of managing constraints according to the Theory of Constraints. Hseuh proposes a new design for a bidirectional automated guided vehicle (AGV)system using simulation in which two AGV's can exchange their loads and their vehicle numbers when they move in the opposite direction

Boruvka, Manlig and Kloud et al., [7]

Determines the minimum number of pallets necessary for ensuring the maximum utilization of production lines. Using specific examples, it is shown that the elimination of $5 \%$ bottlenecks leads to approx. $5 \%$ increase in production.

Govaert.T et al., (2009) [8]

To draw buffers manually, it would take too consuming, especially at the border of the line or while changing plant layout. In the case of kitting the configuration of buffers will change with the type of transport.

\section{E. E. Adan R Ebeit et al., (2001) [9]}

After the simulation, the bottleneck analyzer option shows the status of every work station and their weight related to the reference time of $8 \mathrm{hrs}$

S Borojevic et al., (2011) [10]

Simulation can be used for decision support with supply chain management, workflow and throughput analysis, facility layout design, resource usage, and allocation and process change

\section{Milan Filo et al., (2013) [11]}

Plant simulation (Tecnomatix) deals with the field of dynamic simulation used to optimize production and its performance also correcting logistic flows and creating their digital models this enables to perform various experiments and scenarios in production. It provides extensive analytical tools to analyze obstacles, statistics and graphs to access profitability.

Yang T, Zhang D et al., (2008) [12]

Buffers primarily hold for 0 to 5 products with only one buffer. Further, the increase in the number of workers has no impact on the throughput of the system or on the average life span of the products

\section{Chung C et al., (2003) [13]}

The model validation in the process of ensuring that the model represents reality. Statistical validity was performed by statistically comparing the output from the actual system with the data from the model that was developed by software

Vamsi k et al., (2009) [14]

Availability is defined as a percentage measure or degree to which machinery and equipment is in an operable and committable state at the point in time when it is needed.

Steffen Bangsow et al., [15]

The stack file and queue file are one-dimensional lists which are accessed according to the FIFO (first in first out, queue) or LIFO (last in first out, stack) principle. The new entries will be inserted into the stack file at the top of the list the last element inserted is the first entry which will be removed.

\section{Data Collection}

\section{The Layout of Body in white:}

This is the replica of the Body in White process layout which undergoes several General

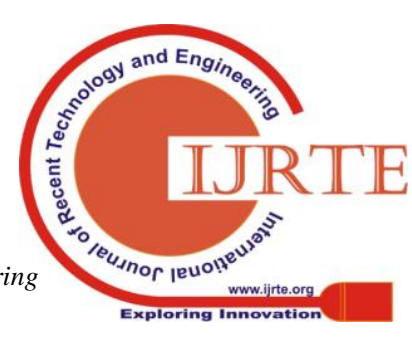


assembly stages within the automobile manufacturing plant. Here the rear subassembly, front subassembly, and middle floor parts are assembled in the underbody process. Side panel inner left and right, side panel outer left and right parts are assembled in framing. Doors and tailgate are assembled later. After that finishing and inspection are done.

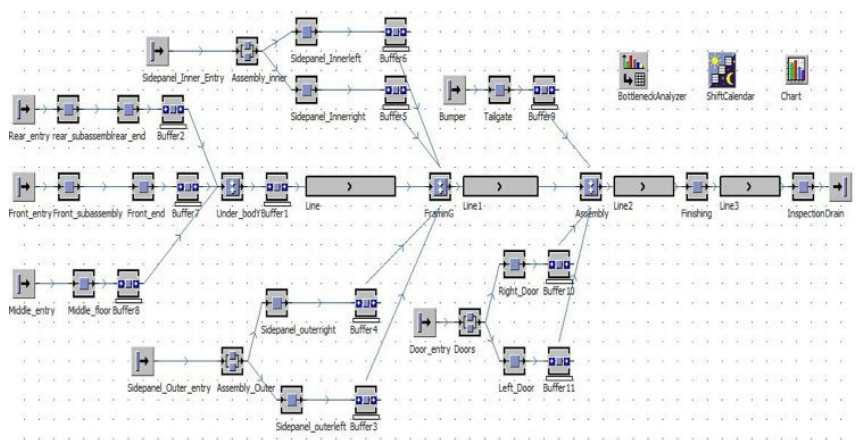

Fig 2: Conceptual Layout of Body in white Department

\section{Shift:}

Three shifts were given

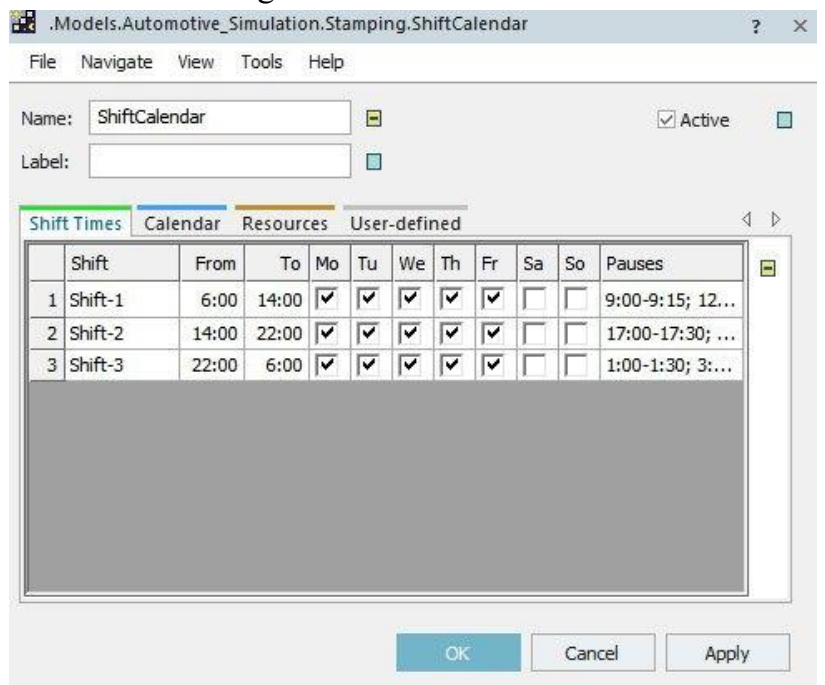

Fig 3: Shifts for Body in white

Times:

\begin{tabular}{|c|c|c|}
\hline Name & Processing Time & $\begin{array}{c}\text { Set Up } \\
\text { Time }\end{array}$ \\
\hline $\begin{array}{c}\text { Rear } \\
\text { subassembly }\end{array}$ & $1: 15$ & $0: 05$ \\
\hline $\begin{array}{c}\text { Front } \\
\text { subassembly }\end{array}$ & $1: 15$ & $0: 05$ \\
\hline Middle floor & $1: 05$ & $0: 03$ \\
\hline Front end & $0: 50$ & $0: 03$ \\
\hline Rear end & $0: 50$ & $0: 03$ \\
\hline $\begin{array}{c}\text { Side panel } \\
\text { Inner left }\end{array}$ & $1: 20$ & $0: 04$ \\
\hline
\end{tabular}

\begin{tabular}{|c|c|c|}
\hline $\begin{array}{c}\text { Side panel } \\
\text { Inner right }\end{array}$ & $1: 20$ & $0: 04$ \\
\hline $\begin{array}{c}\text { Side panel } \\
\text { outer left }\end{array}$ & $1: 15$ & $0: 04$ \\
\hline $\begin{array}{c}\text { Side panel } \\
\text { outer right }\end{array}$ & $1: 15$ & $0: 04$ \\
\hline Under-body & $2: 40$ & $0: 10$ \\
\hline $\begin{array}{c}\text { Framing } \\
\text { Assembly }\end{array}$ & $4: 10$ & $0: 09$ \\
\hline Finishing & $0: 50$ & $0: 04$ \\
\hline Inspection & $0: 30$ & $0: 01$ \\
\hline Tailgate & $0: 50$ & $0: 04$ \\
\hline Left door & $0: 40$ & $0: 08$ \\
\hline Right door & $0: 40$ & $0: 08$ \\
\hline Assembly & $0: 50$ & $0: 05$ \\
\hline inner & $0: 50$ & 05 \\
\hline Assembly & & \\
\hline outer & & $0: 05$ \\
\hline
\end{tabular}

\section{Methodology USED}

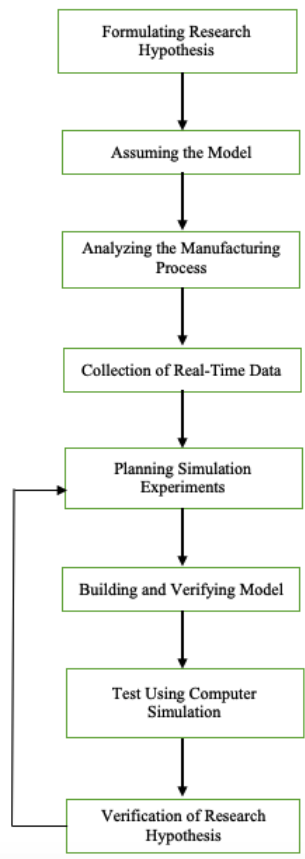

Fig 4: Procedure for Conducting Simulation Layout Model 


\section{RESULTS}

These results are obtained for seven days of time

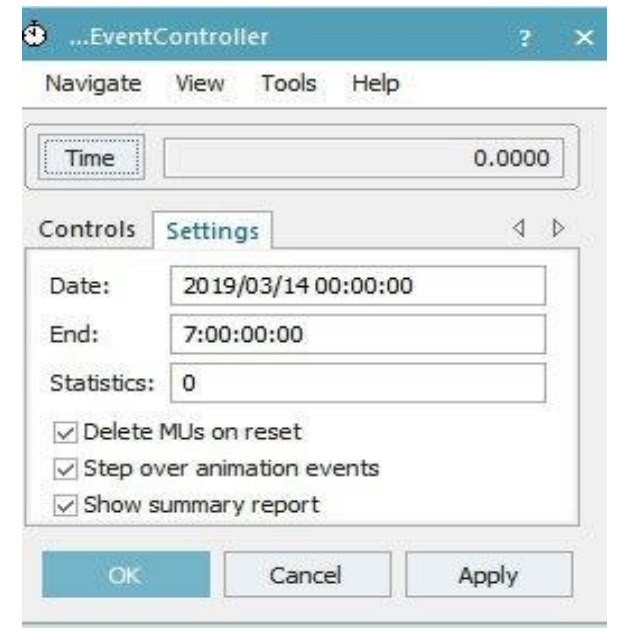

Fig 5: Schedule time for the Body in white

The Throughput without Buffer:

Simulation time: 7:00:00:00.0000

Cumulated Statistics of the Parts which the Drain Deleted \begin{tabular}{|c|c|c|c|c|c|c|}
\hline Object & Name & Mean Life Time Throughput & TPH Production Transport Storage Value added & Portion \\
\hline
\end{tabular} Body.Drain Container $\quad 5: 35.3109$

Fig 6: Throughput without Buffer for Body in White

\section{The Bar chart without Buffer:}

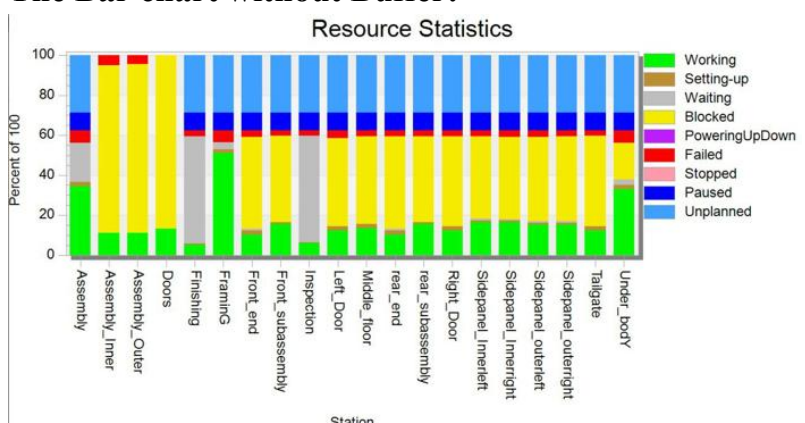

Fig 7: Performance of body in white without Buffer Placed Buffers before the processes where time is wasted.

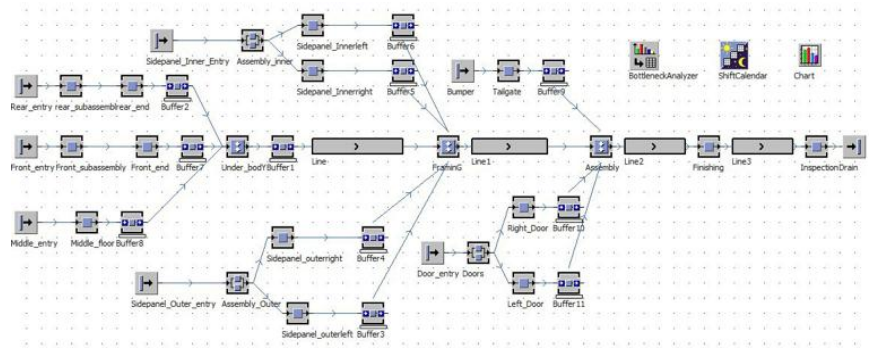

Fig 8: Buffers in the layout for Body in white

The Throughput with Buffer:

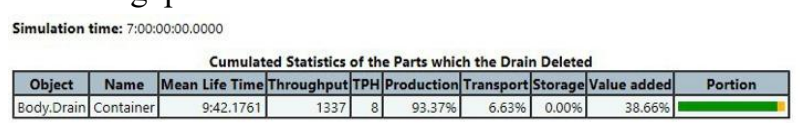

Fig 9: Throughput with Buffer for Body in White

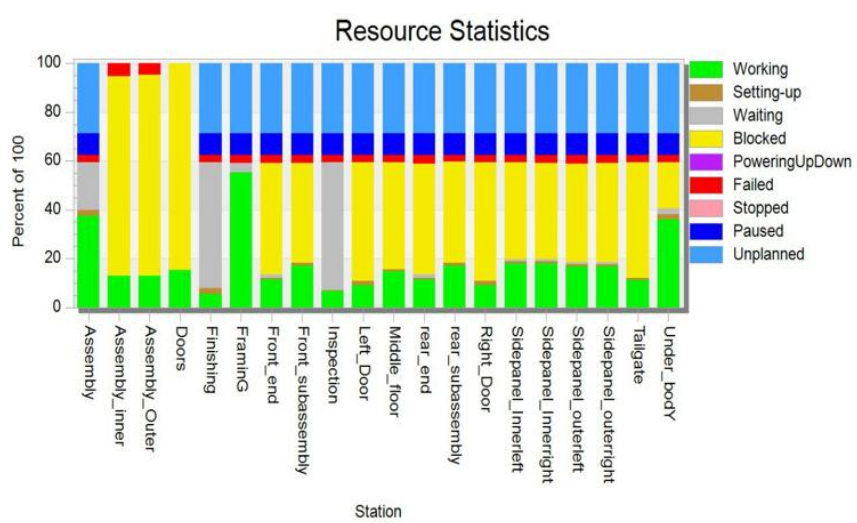

Fig 10: Performance of body in white with Buffer

\section{RESULTS AND DISCUSSION}

From the performance graphs, the throughput obtained at the end of the process without using buffer is 1234 with the production percentage of $94.23 \%$, whereas with the usage of buffer the throughput obtained is 1337 which shows an increase of $7.7 \%$ with the production percentage of $93.37 \%$.

\section{CONCLUSION}

The problem of a bottleneck is one of the main issues faced by production organizations. The result of the paper is experimentally verified by using Plant simulation software. The performance of the body in white process is measured by calculating the throughput. DES can be applied successfully for improving the production line. The results show a reduced disparity between the stations. The productivity increased relative to capacity and the arrival time. The simulation model is improved in order to get a balanced output with in the best time by avoiding as many problems as possible. The Bottlenecks in the system is reduced for a better work flow, It is reduced by placing buffers before the processes and the throughput has been increased. The future research on such works can be towards automating the manual systems with an objective of high productivity.

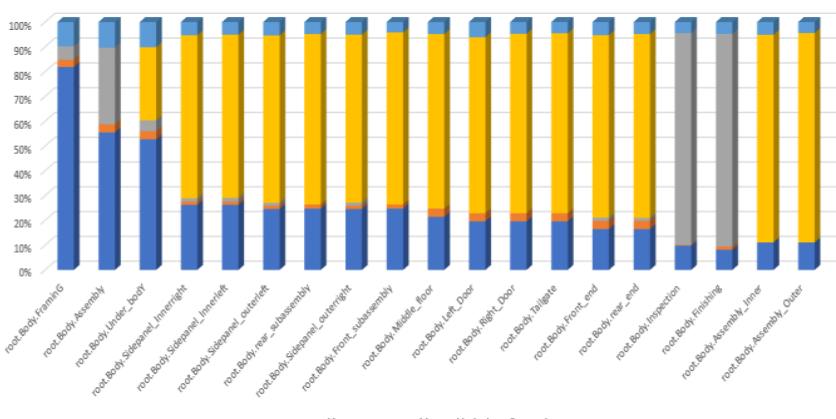

Fig 11: Times of the process without buffer 


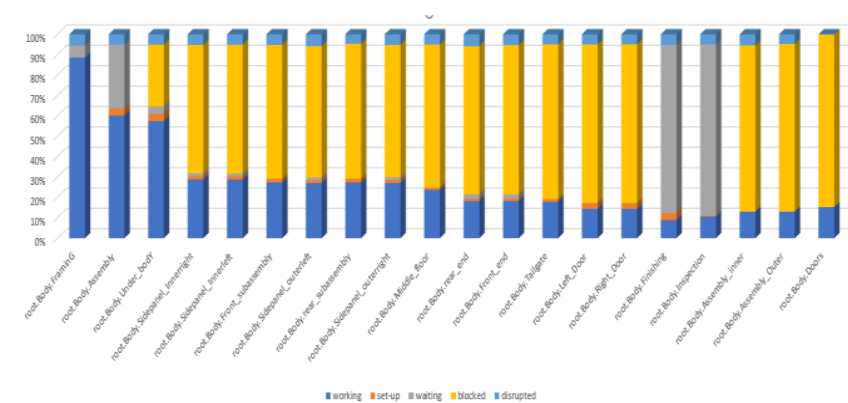

Fig 12: Times of the process with buffer

\section{REFERENCES}

1. Banks, Jerry. Handbook of Simulation. Atlanta: John Wiley \& Sons, Inc., 1998. ISBN 0-471-13403-1.

2. Artid. Trakultongchai, Srisawat. Supsomboon, and Kamol. Limtanyakul "Process Simulation and Improvement of Automotive Paint Shop". International Journal of Mining, Metallurgy \& Mechanical Engineering (IJMMME) Volume 1, Issue 1 (2013) ISSN 2320-4060 (Online)

3. Julia SIDERSKA "Application of tecnomatix plant Simulation for modelling production And logistics processes". Business, Management and education ISSN 2029-7491 / eISSN 2029-6169

4. Ting Yang, Dinghua Zhang, Bing Chen, Shan Li "Research on Plant Layout and Production Line Running Simulation in Digital Factory Environment". 2008 IEEE Pacific-Asia Workshop on Computational Intelligence and Industrial Application

5. Mateusz Kikolski "Identification of production bottlenecks with the use of Plant Simulation software". DOI: $10.1515 / \mathrm{emj}-2016-0038$

6. "Applying discrete event simulation and an automated bottleneck analysis as an aid to detect running production constraints". Proceedings of the 2005 Winter Simulation Conference M. E. Kuhl, N. M. Steiger, F. B. Armstrong, and J. A. Joines, eds.

7. Abass Enzi, Ahad Ali and James A. Mynderse "Using Simulation Modeling To Increase Plant Throughput". Proceedings of the 2016 International Conference on Industrial Engineering and Operations Management Detroit, Michigan, USA, September 23-25, 2016

8. Victoria V. Kokareva, V.G. Smelov "Production Process Management by simulation in Tecnomatix plant simulation" Article · April 2015 DOI: 10.4028/www.scientific.net/AMM.756.604

9. Florin Blaga, Iulian Stanăşel, Voichița Hule, and Alin Pop "Balancing the manufacturing lines through modelling and simulation using Tecnomatix Plant Simulation" MATEC Web of conferences 112,06012(2017)

10.Marek Kliment, Peter Trebun̆a, Martin Straka "Tecnomatix Plant Simulation, Its Features and Its Integration into Business Processes in Logistics

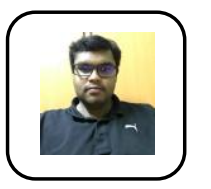

D.Phanindra Kshatra, working as Assistant Professor in the Department of Mechanical Engineering of Koneru Lakshmaiah Educational Foundation of Andhra Pradesh state in India. He has published many International journals in various reputed Journals. His area of interests are Discrete Event Simulation, DES in Lean, Lean Flow, Kanban Systems and Simulation methodologies. At present his area of research is going on Discrete Event Simulation for Automobile Manufacturing

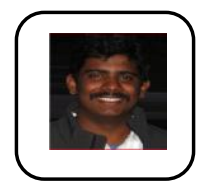

P. Ratna Prasad, working as Assistant Professor in the Department of Mechanical Engineering of Koneru Lakshmaiah Educational Foundation of Andhra Pradesh state in India. He has published many International journals in various reputed Journals. His area of interests is Discrete Event Simulation, Robotics, Human Exoskeleton methodologies and simulation, Gait analysis. At present his area of research is going on Applications of Simulation in Medical and Automobile Field.

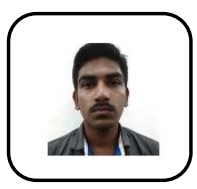

Md. Kalamulla is a IV Year, B-Tech Mechanica Engineering Student at K L University, Vaddeswaram, Guntur (DT)

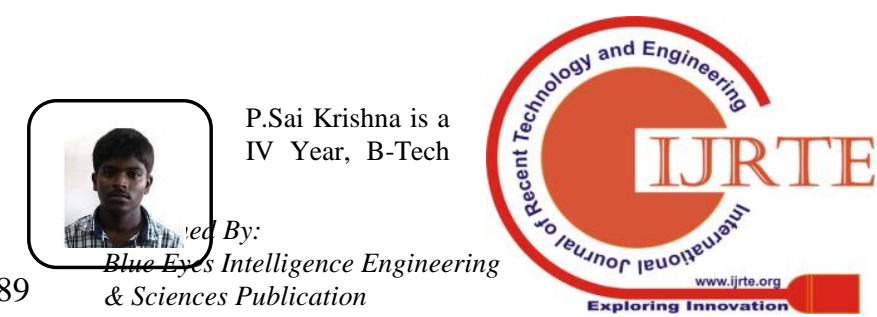


Mechanical Engineering Student at $\mathrm{K}$ L University, Vaddeswaram, Guntur (DT)

P.B.L.N. Sai is a IV Year, B-Tech Mechanical Engineering Student at K L University, Vaddeswaram, Guntur (DT) 